\title{
A Escatologia cristã no Prognosticum futuri saeculi de Juliano de Toledo
}

\author{
Christian Eschatology in Julian of Toledo's \\ Prognosticum futuri saeculi
}

César Andrade Alves

\section{Resumo}

Ao longo da plurissecular história da Teologia, a apresentação da Escatologia cristã foi adquirindo a feição que, no início do século $\mathrm{XX}$, demonstrava-se tipicamente nos tratados intitulados De Novissimis. Estes receberam notável influência da primeira síntese de Escatologia, intitulada Prognosticum futuri saeculi. Ela foi elaborada em 688 por Juliano de Toledo. O influxo dessa obra seminal sobre aqueles tratados se deu tanto na estrutura como no conteúdo. Eles focavam as realidades cronologicamente últimas mediante uma hermenêutica não simbólica, literalista. Apesar de sua grande influência, a obra de Juliano de Toledo é ainda inédita e geralmente desconhecida no Brasil. Sua apresentação e comentário tornam-se assim relevantes em nosso contexto, pois nos ajudam a conhecer melhor a história da Teologia. Isso ajudará a enriquecermo-nos com os valores da obra de Juliano e, ao mesmo tempo, a não incorrermos hoje em suas lacunas, o que será proveitoso para apresentar, no modo requerido pelo nosso tempo, o definitivo de Deus: 1) que já se manifestou, como Escatologia realizada, no evento Jesus Cristo; 2) que pode se manifestar, como Escatologia presente, na vida dos fiéis antes da morte; e 3) que se manifestará, como Escatologia futura, na realidade final.

Palavras-chave: Renovação escatológica. De Novissimis. Antropologia Teológica. Cristologia. 


\begin{abstract}
Over the centuries of Church history, it was gradually that the presentation of Christian Eschatology got the features shown in the typical De Novissimis treatises at the beginning of 20th century. These treatises were greatly influenced by the first synthesis in Eschatology entitled Prognosticum futuri saeculi. It was written in 688 by Julian of Toledo. The influence of this seminal work on those treatises was on both their structure and contents. They focused on the chronologically last realities through a literalistic, nonsymbolic hermeneutics. In spite of its great influence, in Brazil Julian of Toledo's work is still unpublished and generally unknown. For this reason, its presentation and commentary become relevant in our context. They contribute to a better understanding of the history of Theology. That would help us to be enriched by the Prognosticum values, and concurrently to avoid falling into its deficiencies. Such things are fruitful to present, as our time demands, God's definitive truth that: 1) was expressed as realized Eschatology in the event of Jesus Christ; 2) can be expressed as present Eschatology in the existence before death; and 3) will be expressed as future Eschatology in the final reality.
\end{abstract}

Keywords: Eschatological renewal. De Novissimis. Theological Anthropology. Christology.

\title{
Introdução
}

Ao longo do século XX, a Escatologia cristã passou por uma profunda renovação queresgatou elementos do depositumfideique, embora fundamentais, havia séculos estavam como que esquecidos, como se houvessem perdido sua antiga e original importância. As renovações bíblica, patrística, litúrgica e ecumênica em curso nos séculos XIX e XX possibilitaram um contato mais vivo com a revelação fundamental trazida por Cristo e testemunhada pelos apóstolos. Foi um fabuloso processo que alcançou a Teologia em geral, e a Escatologia em particular. Em tal processo foi deveras valioso o trabalho exegético e teológico mediante o método histórico-crítico. Sobre este, em 1943 o papa Pio XII já anotava que "a nossa época [...] graças a Deus oferece 
à exegese novos meios e instrumentos", ${ }^{1}$ e que tais meios "foram concedidos ao nosso tempo não sem o previdente conselho de Deus". ${ }^{2}$

Antes daquela renovação no campo da Escatologia cristã, no início do século XX uma obra representativa do estado então atual nesse campo era aquela de Louis Billot, professor jesuíta na Pontifícia Universidade Gregoriana em Roma. Trata-se do clássico livro intitulado De Novissimis, publicado originalmente em 1902 e que teve sucessivas reedições. A terceira edição, em 1908, tinha como estrutura os seguintes capítulos: ${ }^{3}$

Capítulo 1: A morte como término da vida.

Capítulo 2: O estado das almas após a morte, no inferno, purgatório e céu. Capítulo 3: A ressurreição universal.

Capítulo 4: O juízo final e a definitiva ordem geral.

Quanto ao conteúdo, os temas no De Novissimis de Billot focavam nos eventos cronologicamente futuros, seja no âmbito do indivíduo (após sua morte), seja no âmbito cósmico (parusia do Senhor, ressurreição geral e juízo final). Uma ampla gama de detalhes era fornecida a respeito da ressurreição e do juízo. Tal estrutura e conteúdo eram desenvolvidos mediante uma hermenêutica bíblica literalista das passagens relevantes. Elas eram lidas como descrições factuais, não figuradas, de acontecimentos que cronologicamente ainda estavam por se verificar.

$\mathrm{Na}$ verdade, havia séculos que o estudo do que hoje denominamos Escatologia cristã se fazia de modo semelhante à estrutura, aos conteúdos, à riqueza de detalhes e à hermenêutica literalista da obra de Billot, que é apenas um exemplo mais recente. No início do século XX tratava-se de uma situação que já perdurava havia muito tempo, um quadro geral plurissecular que aparentava consolidado, e diante do qual podia parecer que não havia perspectivas de ulteriores desenvolvimentos. De fato, em 1911 o teólogo protestante Ernst Troeltsch chegou a comentar nesse sentido:

Um teólogo moderno disse que, hoje em dia, o escritório da Escatologia encontra-se, de modo geral, fechado. [...] Pensar em punições e retribuições

\footnotetext{
${ }^{1}$ DAS 19.

${ }^{2}$ DAS 11.

${ }^{3}$ BILLOT, L., De Novissimis, p. 9.
} 
traz cada vez mais uma sensação insuportável. $O$ além não pode ser outra coisa senão a manifestação gradual da consequência produzida por uma vida [levada de modo] superior, e um crescimento interior cada vez mais profundo no divino reino espiritual. ${ }^{4}$

Contudo, aquelas quatro renovações mencionadas no início - bíblica, patrística, litúrgica e ecumênica - permitiram vislumbrar cenários diferentes no campo da Escatologia. Em meio a choques e dores, o processo renovador iniciou-se no final do século XIX e prosseguiu ao longo do século XX. Começou no âmbito da Teologia, e depois chegou ao Magistério.

O primeiro passo significativo para a renovação do tratado da Escatologia cristã foi empreendido pelo teólogo e exegeta protestante alemão Johannes Weiss com um livro publicado em 1892 que exerceu notável influência. ${ }^{5}$ Situava-se em oposição à Teologia Liberal em voga na época (corrente na qual se situava, por exemplo, o supracitado Troeltsch), cujo enfoque a respeito de Jesus era imanentista e meramente ético. As intuições de Johannes Weiss compõem a primeira obra moderna de exegese crítica neotestamentária feita na ótica da Escatologia. A pesquisa crítica de Weiss identificava, na compreensão e no ensinamento de Jesus, o conceito central de Reino de Deus e de sua iminente chegada ao mundo. Em oposição à Teologia Liberal, Weiss resgatou alguns elementos centrais do Novo Testamento: 1) a sustentação de que a expectativa de Jesus era transcendente em relação à imanência do mundo; 2) que tal expectativa fundava-se na intervenção de Deus na história da humanidade e do cosmo; 3) que, na compreensão do próprio Jesus, o Reino de Deus consistiria na chegada, no cumprimento e no fim iminente da história em sintonia com a visão apocalíptica judaica. Na sequência de Johanness Weiss, outros autores e obras relevantes para a renovação da Escatologia cristã foram:

- no âmbito protestante, Albert Schweitzer, Karl Barth, Charles H. Dodd, Oscar Cullmann, Joachim Jeremias, Wolfhart Pannenberg e Jürgen Moltmann; ${ }^{6}$

\footnotetext{
${ }^{4}$ TROELTSCH, E., Glaubenslehre, p. 36.

${ }^{5}$ WEISS, J., Die Predigt Jesu vom Reiche Gottes, p. 1-70.

${ }^{6}$ SCHWEITZER, A., Von Reimarus zu Wrede, p. 1-418; BARTH, K.; Der Römerbrief, p. 3-783; BARTH, K.; Die Auferstehung der Toten, p. 1-125; DODD, C. H., The Parables of the Kingdom, p. 3-214; CULLMANN, O., Christus und die Zeit, p. 3-224; JEREMIAS, J., Die Gleichnisse Jesu, p. 9-152; PANNENBERG, W., Dogmatische Thesen zur Lehre von der Offenbarung, p. 91-114; MOLTMANN, J., Theologie der Hoffnung, p. 11-338.
} 
- no âmbito católico, Hans Urs Von Balthasar, Jean Daniélou, Pierre Teilhard de Chardin, Yves Congar e Karl Rahner. ${ }^{7}$

Podem ser brevemente elencadas algumas características desse trabalho de renovação na apresentação da Escatologia cristã. Há uma resoluta inserção da reflexão no quadro da história da salvação. Com um grau maior de fidelidade ao dado revelado, fala-se agora de uma Escatologia realizada, uma Escatologia presente - ou que se realiza - e uma Escatologia futura. A Escatologia é uma reflexão sobre a dimensão definitiva do Reino de Deus que se realizou em Jesus; nesse sentido, uma Escatologia já realizada no passado. Mas não se trata apenas de algo do passado. Os conteúdos da Escatologia são reinterpretados à luz da centralidade cristológica. Cristo é o horizonte último da Escatologia. A Escatologia é uma reflexão também sobre o tempo da vida humana antes da morte, na medida em que ali o definitivo de Deus já se verifica também; nesse sentido, uma Escatologia presente, que se realiza antes da morte. Mas não se trata apenas do passado e do presente. A Escatologia cristã fala também de coisas que ainda não aconteceram historicamente; nesse sentido, uma Escatologia futura a se verificar depois da morte. Desse modo, passou-se de uma reflexão sobre acontecimentos do futuro, para uma reflexão sobre o último, no sentido de definitivo, que se encontra: no evento de Cristo já acontecido, no presente (na vida do fiel antes da morte) e no futuro (logo após a morte e no final dos tempos). Ao falar do futuro, contudo, passa-se de um fornecimento de detalhes abundantes que iam muito além do dado revelado, e de uma hermenêutica bíblica sobre as passagens relevantes que era literalista, como descrições factuais do futuro, para outra mais de acordo com a linguagem simbólica e sóbria do Novo Testamento. Na renovação da apresentação da Escatologia cristã, o vínculo da Escatologia com a Cristologia se mostrou mais do que nos doze ou treze séculos anteriores - não só evidente, mas, principalmente, de absoluta importância. Fez-se novamente patente (como o tinha sido no tempo de Cristo e das gerações do tempo dos apóstolos, isto é, do depositum fidei) que o evento Cristo - já acontecido - representou o

\footnotetext{
${ }^{7}$ VONBALTHASAR, H. U., Geschichte des eschatologischen Problems in der modernen deutschen Literatur, p. 3-219; VON BALTHASAR, H. U., Eschatologie, p. 403-421; DANIÉLOU, J., Christologie et eschatologie, p. 269-286; TEILHARD DE CHARDIN, P., Le Phénomène humain, p. 3-348; TEILHARD DE CHARDIN, P., L'Avenir de l'homme, p. 5-405; CONGAR, Y. , Le purgatoire, p. 279-336; RAHNER, K., Theologische Prinzipien der Hermeneutik eschatologischer Aussagen, p. 401-428.
} 
definitivo de Deus (nesse sentido, o escatológico) já acontecido na história. Algo característico do futuro escatológico do final dos tempos (que de fato ainda não aconteceu) já se fez presente como evento na história do cosmo. Algo que seria típico só do final dos tempos já aconteceu de modo antecipado: a vida, paixão, morte e ressurreição de Jesus Cristo. A esse respeito, no Novo Testamento o emprego do verbo no passado não é recurso metafórico. Paulo descreve no passado: "quando chegou a plenitude do tempo, enviou Deus o seu Filho, nascido de uma mulher" (Gl 4,4). A carta aos Hebreus também o põe no passado: "nesses dias que são os últimos [eschátou], Deus nos falou por meio do Filho" (Hb 1,2). Em João, o evento Cristo, quando aconteceu, foi como o "o vinho melhor guardado até agora" (Jo 2,10). Também em Marcos: "o tempo se cumpriu" (Mc 1,15). A vida de Jesus Cristo, desde a encarnação à ressurreição, significou o definitivo de Deus que já aconteceu, o vinho bom "guardado até agora".

Mas como foi possível que, ao longo dos séculos da história da Teologia, a apresentação da Escatologia cristã fosse adquirindo a feição que demonstrava no início do século XX, da qual o De Novissimis de Louis Billot é um exemplo?

Parte importante da resposta é a primeira síntese de Escatologia na história da Igreja, elaborada por Juliano de Toledo em 688 e intitulada Prognosticum futuri saeculi (antevisão do mundo que há de vir). Não se conhece outra obra, anterior a ela ou sua contemporânea, que tenha reunido sistematicamente as reflexões no campo da Escatologia. Alcançou grande difusão durante os séculos seguintes e tornou-se, no período medieval, a principal referência na sua área. "O livro se encontra, muitas vezes em dois ou três exemplares, em quase todas as bibliotecas [da cristandade] desde o século IX até o século XII" ${ }^{8}$ Influenciou sobremaneira as apresentações medievais nesse campo. "A influência do Prognosticon é sobretudo de natureza estrutural. Os três livros que compõem a obra, com efeito, sustentam o plano dos estudos seguintes (pelo menos para os do século XII)". ${ }^{9}$ Além da influência estrutural, a obra estimulou poderosamente as reflexões da Teologia medieval nesse campo a se desenvolverem com duas características de conteúdo que permaneceriam vigorosas até o século XX: 1) uma consideração focada nas realidades últimas em sentido cronológico, que ainda não aconteceram, futuras; 2) a consideração desses eventos futuros mediante uma hermenêutica não simbólica, tão

\footnotetext{
${ }^{8}$ HILlGARTH, J. N., El Prognosticon futuri saeculi de San Julián de Toledo, p. 17.

${ }^{9}$ ANCONA, G., Prognosticon futuri saeculi, p. 162.
} 
descritivas como quaisquer narrativas factuais do passado. "A Escatologia de Juliano era conhecida e foi assimilada, em suas linhas principais, por um importante autor, Pedro Lombardo, cuja obra filosófico-teológica teve notável influência sobre o desenvolvimento de toda a Teologia Escolástica". ${ }^{10}$

O Prognosticum futuri saeculi de Juliano de Toledo é, portanto, uma obra de grande mérito no tempo em que foi composta, há mais de 1.300 anos, da qual as edições clássicas são pelo menos duas. ${ }^{11}$ É, contudo, praticamente desconhecida no Brasil. Alguns compêndios de Escatologia cristã aqui publicados dedicam a ela duas ou três páginas, ${ }^{12}$ enquanto outros nem sequer a mencionam. ${ }^{13}$ Em outros contextos a obra de Juliano de Toledo é conhecida ${ }^{14}$ e recebeu traduções. ${ }^{15}$ No Brasil, entretanto, é desconhecida e ainda inédita, sem qualquer tradução. Sua apresentação e comentário, feitos a seguir, tem por isso relevância em nosso contexto. Ajuda-nos a conhecer melhor a história da Teologia, para enriquecer-nos com seus valores e não incorrermos hoje em suas lacunas. Empregaremos sua tradução em inglês, cuja edição tem um aparato de comentários mais extenso. ${ }^{16}$

\section{Sitz im Leben e natureza da obra}

No início do século $\mathrm{V}$, as invasões bárbaras haviam produzido, na península ibérica, o Reino Visigótico. Com a conversão dos visigodos ao catolicismo em 589, uma nova e dinâmica sociedade religiosa fora criada

${ }^{10}$ STANCATI, T., Preface and Introduction, p. 257.

11 JULIANO DE TOLEDO, Prognosticum futuri saeculi libri tres, p. 3-126; JULIANO DE TOLEDO, Prognosticon futuri saeculi libri tres, col. 453-524.

${ }^{12}$ LADARIA, L., De Agostinho a Juliano de Toledo, p. 369-371; ANCONA, G.; Prognosticon futuri saeculi, p. 162-164.

${ }^{13}$ SCHMAUS, M.; A fé da Igreja, p. 150-242; LIBANIO, J. B.; BINGEMER, M. C. L., Escatologia cristã, p. 15-289; NOCKE, F. J., Escatologia, p. 339-426; MURAD et al., Da terra ao céu, p. 11-165. ${ }^{14}$ WICKI, N., Das Prognosticon futuri saeculi Julians von Toledo als Quellenwerk der Sentenzen des Petrus Lombardus, p. 349-360; HILlGARTH, J. N., El Prognosticon futuri saeculi de San Julián de Toledo, p. 5-61; POZO, C., La doctrina escatológica del Prognosticon futuri saeculi de San Julián de Toledo, p. 173-201; GONZÁLEZ RUIZ, R., San Julián de Toledo en el contexto de su tiempo, p. 7-21; STANCATI, T., Alle origini dell'Escatologia cristiana sistematica, p. 400-433; GARCÍA HERRERO, G., Notas sobre el papel del Prognosticum futuri saeculi de Julián de Toledo en la evolución de la idea medieval del purgatorio, p. 503-513.

${ }_{15}$ JULIANO DE TOLEDO, Prognosticum futuri saeculi, p. 371-464; JULIANO DE TOLEDO, Pronóstico del mundo futuro, p. 45-166.

${ }^{16}$ A tradução em JULIANO DE TOLEDO, Prognosticum futuri saeculi (PFS), p. 371-464. Ver também seu comentário: STANCATI, T., Preface and Introduction, p. xi-362. 
na região, "começando um novo estado unificado no qual a Igreja tinha um papel central e se encontrava ativamente envolvida". ${ }^{17}$ Foi, nesse contexto mais amplo e dinâmico da Hispania do tempo dos visigodos, e dos primeiros séculos da cristandade europeia, que Juliano nasceu em 642 em Toledo - a capital do reino -, viveu e morreu como bispo dessa mesma cidade em 690.

É de sua autoria a primeira síntese, escrita em forma de tratado sistemático, a respeito da Escatologia da Sagrada Escritura e da Época Patrística. Tal obra, o Prognosticum futuri saeculi, "é o primeiro exemplo na História de uma sistematização de temas e textos de Escatologia num único códice manuscrito". ${ }^{18} \mathrm{O}$ livro sistematiza elementos de Escatologia provenientes tanto da Bíblia, como de doze autores da Época Patrística, quase todos latinos. O mais citado é Agostinho, seguido de Gregório Magno, Ildefonso de Toledo, Juliano Pomério e Isidoro de Sevilha. Da Patrística grega são citados João Crisóstomo e Orígenes. Outros autores da Patrística Latina que ali aparecem são Jerônimo, Cipriano de Cartago, Eugênio de Toledo, Ambrósio e Cassiano.

O próprio texto da obra possui uma introdução onde Juliano descreve o contexto imediato em que o trabalho surgiu. Juliano era já bispo de Toledo, a principal cidade e diocese da Espanha na época. Um dos concílios de Toledo, o décimo-quinto, ${ }^{19}$ terminara havia poucos dias. Na Semana Santa, após celebrar a "Festa da Paixão do Senhor" (Sexta-feira Santa) ${ }^{20}$ com o povo e seu amigo e bispo Idálio de Barcelona, ambos se retiraram para um lugar sossegado para rezar e conversar, ainda no clima de compunção pela celebração da morte de Jesus. "Uma alegria sublime brotou em nossas mentes e repentinamente fomos elevados ao mais alto nível de contemplação". ${ }^{21}$ Ali o interesse deles foi compelido com fervor para o tema do estado das pessoas após a morte, porém especificamente antes da ressurreição. Tal experiência gerava uma obra escrita que influenciaria a reflexão teológica no campo da Escatologia por mais de um milênio. "Os dois bispos começaram a se perguntar entre si acerca do estado das almas entre o evento de sua morte corporal e o evento final da ressurreição universal. Este foi o verdadeiro núcleo do diálogo e, igualmente, no texto do Prognosticum, consiste no mais importante tema teológico de

\footnotetext{
${ }^{17}$ STANCATI, T., Preface and Introduction, p. 248.

${ }^{18}$ STANCATI, T., Preface and Introduction, p. 227.

${ }^{19}$ STANCATI, T., Preface and Introduction, p. 186.

${ }^{20}$ PFS Praefatio.

${ }^{21}$ PFS Praefatio.
} 
todo o livro". ${ }^{22}$ Faziam-se mutuamente várias perguntas a esse respeito, sem, contudo, alcançarem respostas plenamente satisfatórias.

\section{Método e objetivo de Juliano}

Juliano e Idálio resolveram colocar por escrito todas as perguntas que haviam surgido. Além do tema do estado das almas depois da morte, porém especificamente antes da ressurreição, viram que, deviam também recolher perguntas sobre a morte e sobre a ressurreição final dos corpos. ${ }^{23}$ Determinaram que as respostas para elas precisavam provir de dois lugares: "conforme aquilo que o pensamento dos mestres católicos havia definido, e [...] a Sagrada Escritura". ${ }^{24}$ Essa estrutura metodológica permeia de fato toda a obra. Em cada questão, primeiramente se enuncia a tese como título, e seguese sua demonstração. Esta quase sempre é feita começando a partir das fontes bíblicas, e complementada com uma ponderada seleção de trechos de autores da época patrística. Tudo é entremeado, tecido e mantido coeso mediante as reflexões de Juliano, tanto ao longo do texto como em seu final. ${ }^{25}$

Acertaram ambos que Juliano se encarregaria de compor um volume com as questões e as respectivas respostas que haviam encontrado naquele dia memorável. "Na verdade, o Prognosticum foi redigido por Juliano num período posterior ao diálogo teológico ocorrido com Idálio. É difícil afirmar com precisão quando Juliano compôs seu trabalho, mas provavelmente isso aconteceu nos meses seguintes à conversação, entre a Páscoa e o outono de 687/688". ${ }^{26}$

$\mathrm{Na}$ intenção de Juliano e Idálio havia uma expressa preocupação pastoral por detrás daquele trabalho reflexivo. "O objetivo do Prognosticum está inteiramente relacionado à fé dos crentes, que precisam receber conhecimentos racionais e lógicos acerca das coisas futuras, e serem alimentados com elementos didáticos e doutrinais". ${ }^{27}$ Mais do que saciar mera curiosidade particular, conforme as palavras do próprio Juliano, a finalidade do trabalho era de cunho pastoral, visando facilitar a compreensão do povo de Deus a respeito de tais assuntos:

\footnotetext{
${ }^{22}$ STANCATI, T., Preface and Introduction, p. 187.

${ }^{23}$ PFS Praefatio.

${ }^{24}$ PFS Praefatio.

${ }^{25}$ STANCATI, T., Preface and Introduction, p. 226.

${ }^{26}$ STANCATI, T., Preface and Introduction, p. 188.

${ }^{27}$ STANCATI, T., Preface and Introduction, p. 228.
} 
A reflexão sobre estes assuntos, unificada aqui numa única coleção, poderá atingir mais intensamente as mentes dos mortais já que eles poderão ler aqui, sem esforço, este material. Assim, como que recebendo gratuitamente um alimento, sua razão contrita frutificará oportunamente. [...] De fato, se meditarmos cuidadosamente sobre o que seremos no futuro, creio que raramente, ou nunca, pecaremos. ${ }^{28}$

O método de agregar os temas segundo capítulos e questões não era típico da literatura patrística. Inovador era também o fato de utilizar duas fontes: uma costumeira, a Sagrada Escritura, e outra não usual na época, os autores da Época Patrística no seu conjunto. Mais ainda, a estrutura que articulava toda a reflexão era metódica e sistemática, "e tudo isso quinhentos anos antes da Época Escolástica!"29 Não se tratava de uma mera coletânea de trechos da Escritura ou dos autores patrísticos. "O trabalho de Juliano tem uma estrutura interna lógica, que deriva de um projeto teológico". ${ }^{30}$ Os elementos tirados daquelas fontes vinham dispostos de maneira ordenada, permeado com uma série de afirmações e conclusões significativas e lógicas tanto do ponto de vista metodológico como teológico. ${ }^{31}$

Com esse método recolheram um total de 121 perguntas, assim distribuídas: 1) sobre a morte, 22 questões; 2) sobre a fase entre a morte e a ressurreição, 37 questões; 3) sobre a ressurreição e o julgamento final, 62 questões. $\mathrm{O}$ objeto material de todas elas já estava posto pelo interesse suscitado a ambos no início daquela experiência memorável: "qual seria a condição das almas dos mortos antes da ressurreição do corpo", ${ }^{32}$ flanqueado pela consideração, por um lado, da morte humana e, por outro lado, da futura ressurreição dos corpos e do julgamento final. Em outros termos, o assunto da investigação iniciada por Juliano e Idálio era explícita e unicamente a Escatologia após a morte, a Escatologia ainda não realizada, futura, o éschaton futuro, as realidades cronologicamente últimas do pós-morte.

\footnotetext{
${ }^{28}$ PFS Praefatio.

${ }^{29}$ STANCATI, T., Preface and Introduction, p. xii.

${ }^{30}$ STANCATI, T., Preface and Introduction, p. 166.

${ }^{31}$ STANCATI, T., Preface and Introduction, p. 166.

32 PFS Praefatio.
} 


\section{Escatologia realizada (o evento Cristo) e Escatologia presente (antes da morte do fiel)}

Esses temas ocupam uma extensão mínima da obra em virtude da própria opção metodológica: perguntar-se por temas que começam cronologicamente com a morte. Eles nem sequer aparecem no corpo da reflexão teológica propriamente dita, mas em partes introdutórias, secundárias e periféricas. O início do texto de Juliano de Toledo é uma introdução composta por um prefácio e uma oração, nos quais vem relatada em primeira pessoa a experiência espiritual daquele dia memorável que havia dado início ao trabalho teológico. É nessa introdução que aparecem, ocasionalmente aludidas, as únicas breves expressões que, em toda a obra, se referem ao definitivo de Deus que já se realizou no passado, no evento de Jesus Cristo:

O Redentor de tudo; 33

És, de fato, o único caminho; ${ }^{34}$

O sublime poder de Seu sacratíssimo sangue e o sinal invencível e venerável de Sua cruz. ${ }^{35}$

Igualmente é no prefácio e na oração inicial - fora da investigação propriamente dita - que se encontram as expressões acerca do definitivo de Deus manifestado no tempo da vida de Juliano antes da morte. Ele relembra ali a experiência espiritual, no presente de sua vida, com a realidade do evento escatológico de Jesus Cristo. Juliano manifesta com clareza que a motivação para investigar aquilo que chamamos de Escatologia futura, era a experiência e a consciência do caráter definitivo e salvífico de Cristo vivido pelo fiel antes da morte.

A Escatologia presente, que pode ser vivenciada pelo fiel já antes da morte, é apresentada em sua dimensão subjetiva por meio de figuras de linguagem e descrita como luz, sabor e doçura:

Pegamos a Sagrada Escritura enquanto éramos iluminados pela luz eterna; ${ }^{36}$

\footnotetext{
${ }^{33}$ PFS Praefatio.

${ }^{34}$ PFS Oratio.

${ }^{35}$ PFS Oratio.

${ }^{36}$ PFS Praefatio.
} 
Quem poderia jamais colocar por escrito, ou recontar oralmente, qual o sabor divino que nos tocou a alma, qual doçura da suprema caridade se infundiu em nossa mente mortal? ${ }^{37}$

O definitivo de Deus vivenciado no tempo de vida antes da morte é também apresentado em sua dimensão de revitalização ou soerguimento a partir de uma condição negativa, figuradamente indicada como cegueira e doença:

\begin{abstract}
Possam nossas preces obter do Senhor que qualquer culpa em que eu tenha imprudentemente incorrido neste trabalho, Ele ordene que seja cancelada pelo mérito do amado sangue de nosso Senhor Jesus Cristo, nosso salvador, ${ }^{38}$

Habitando cego e doente no deserto da Idumeia, clamo a Ti, Filho de Davi, que tenha piedade de mim. [...] Tu, que te dignaste mostrar-se a mim como o caminho, alcança-me com tua mão para que, não mais cego, eu veja; ${ }^{39}$
\end{abstract}

Enfim, a Escatologia presente é almejada para a continuidade do período de vida que ainda resta antes da morte. Tal dimensão presente é expressa como companhia constante junto a Cristo, cujo jeito de ser orienta o percurso da existência de Juliano de Toledo:

Peço que possa continuar através de ti, que és o caminho, e em ti, que és a verdade. Que eu nunca tropece, que eu possa alcançar a ti, que és a vida. De ti, que és o caminho à felicidade suprema, que nunca me separe por qualquer motivo que seja, que nunca me distancie, ${ }^{40}$

Alimenta-me com todas as promessas de tua graça que, ainda que não possam ser experimentadas pelos sentidos, cremos poderem ser atingidas mediante a verdadeira firmeza da fé. ${ }^{41}$

\title{
4. Escatologia futura (após a morte do fiel)
}

Desde o início, a proposta de Juliano e Idálio estava dedicada a este tema que, hoje, designamos como Escatologia futura, ou seja, a sorte da pessoa

\footnotetext{
${ }^{37}$ PFS Praefatio.

${ }^{38}$ PFS Praefatio.

${ }^{39}$ PFS Oratio.

${ }^{40}$ PFS Oratio.

${ }^{41}$ PFS Oratio.
} 
desde o período logo após sua morte até o final dos tempos. O próprio Juliano descreve:

Começamos a nos perguntar qual seria a condição das almas antes da ressurreição dos mortos. [...] Além disso, também decidimos anotar [...] os temas e perguntas que havíamos reunido a respeito da ressurreição final do corpo. [...] Além disso, consideramos que esses dois livros seriam também acompanhados e precedidos por outro [...] que trataria da morte do corpo. ${ }^{42}$

Esse é o conteúdo da obra, a sua matéria própria e verdadeira. O conjunto dos três "livros" (na verdade capítulos) que compõem a obra considera unicamente a temática compreendida nesse arco entre a morte e o final dos tempos. Nessa consideração, o esquema adotado é o da Escatologia das duas fases após a morte: uma antes da ressurreição da carne, e outra após.

O centro dessa temática é composto pelo "livro" (capítulo) 2, dedicado àquela parte da Escatologia futura que hoje se refere como Escatologia intermediária. A Antropologia é aquela clássica concepção da dualidade de dois lados bons. Dualidade é concepção distinta do dualismo de cunho platônico. O dualismo considera que um lado da criação é essencialmente bom e que tem valor positivo, e que outro lado da criação é essencialmente mau, com valor negativo. ${ }^{43}$ Ao contrário, a clássica concepção da dualidade de dois lados bons - corpo e alma - é aquela utilizada por Juliano. Tais lados bons podem ser separados de modo que um deles permaneça existindo. Segundo Juliano, antes da morte "permanece a união do corpo e da alma", mas "no momento da nossa morte, passamos para aquela região na qual o corpo se separa da alma". ${ }^{44} \mathrm{O}$ livro (capítulo) 2, ao examinar a Escatologia intermediária, aborda a existência do indivíduo na condição de "apenas alma" entre seus dois períodos corporais: vida corporal antes da morte neste mundo, e vida corporal após a ressurreição da carne no mundo que há de vir:

A contribuição mais original do Prognosticum consiste na elaboração, à qual todo o livro 2 é dedicado, da assim chamada Escatologia intermediária. Neste, de fato, e calcado no dado bíblico e patrístico, o autor desenvolve uma rica teoria acerca da sobrevivência e subsistência providenciais da

\footnotetext{
${ }^{42}$ PFS Praefatio.

${ }^{43}$ CTI, Algunas cuestiones actuales de Escatología, 5.1 (a versão on-line em português ainda não se encontra disponível).

${ }^{44}$ PFS I, q. 18.
} 
alma desde o dramático momento da morte corporal até o evento final da ressurreição geral. Sobre essa situação da alma, Juliano tece uma rede de conexões lógicas, antropológicas e teológicas que, ao final, compõem uma síntese complexa e quase completa dos temas relacionados à condição da alma separada de seu corpo. ${ }^{45}$

Juliano modifica o que Santo Agostinho havia falado a respeito da purificação após o término da presente vida. Juliano propõe o esquema tripartido que se tornaria a base dessa doutrina da purificação pós-morte. Agostinho distinguia, no pós-morte, quatro classes de pessoas: 1) boas (boni), 2) não totalmente boas (non valde boni), 3) não totalmente más (non valde mali), 4) más (mali). Juliano menciona apenas três classes: 1) boas, 2) não totalmente más (non valde mali), 3) más. No esquema de Juliano, é a segunda classe, aquela das almas não totalmente más (non valde mali) que é suscetível de uma purificação após a morte. ${ }^{46} \mathrm{O}$ esquema tripartido de Juliano "tornouse a base da doutrina cristã que, com o passar do tempo, seria chamada de purgatório". ${ }^{47}$ Ele mesmo, contudo, não utiliza tal termo (que só apareceria mais tarde na história da Teologia), mas sim a clássica expressão fogo purificador (ignis purgatorius). ${ }^{48}$ Sistematizando "aquilo que o pensamento dos mestres católicos havia definido, e [...] a Sagrada Escritura", ${ }^{49}$ Juliano apresenta as seguintes conclusões. Logo após a morte já há separação entre felicidade e infelicidade, alegria e sofrimento, nos três graus mencionados. "Quanto ao estado intermediário, a afirmação doutrinal importante constituise da ideia da imediata retribuição logo depois da morte". ${ }^{50}$

Primeiro, o caso dos justos ou santos, e dos mártires. Mesmo antes de ressuscitarem, estes já vão para junto do Senhor ressuscitado. Sem ressuscitarem ainda, estão já ali, assinalados pelo desejo da futura união com o corpo novamente, que será a ressurreição da carne. Ali já acontece para eles uma grande proximidade com Deus. Nas palavras de Juliano, "a substância mesma de Deus, e de Deus Verbo pelo qual todas as coisas foram feitas, pode ser vista e ouvida". ${ }^{51}$ Contudo, não se trata da proximidade máxima.

\footnotetext{
${ }^{45}$ STANCATI, T.; Preface and Introduction, p. 183.

${ }^{46}$ PFS I, q. 22.

${ }^{47}$ STANCATI, T., Preface and Introduction, p. 185.

${ }^{48}$ PFS II, q.19-23.

${ }^{49}$ PFS Praefatio.

${ }^{50}$ ANCONA, G., Escatologia cristã, p. 163.

${ }^{51}$ PFS II, q. 2.
} 
Não corresponde ainda a "ver a imutável substância de Deus como os anjos a vêem", ${ }^{52}$ conforme diz Juliano. Como as pessoas estão incompletas, apenas no estado de almas, não se trata ainda de visão e audição plenas. É Juliano que ressalta que, "contudo, já se poderá alegrar porque, logo após a morte, não ficaremos privados da visão de Deus, mas a desfrutaremos felizmente se tivermos vivido de um modo que Lhe aprouver". ${ }^{53}$

Segundo, há o nível dos que não são totalmente maus e que não merecem ir para o inferno. Como morreram carregando faltas graves, não podem estar junto com os santos e mártires, que já estão vendo a Deus. Para serem salvos, precisam ainda ser purificados, o que acontece mediante o fogo purificador (ignis purgatorius), que é bem diferente do fogo do inferno. Juliano apresenta como base bíblica desse ensinamento a clássica passagem de 1Cor 3,12-15. A purificação temporária é determinada mediante penas medicinais, que visam salvá-los. A força ou intensidade de tais penas medicinais depende do nível de faltas graves que tais pessoas carregam quando morrem. Se for muito longo, o processo de purificação pode se estender até o juízo final. A oração que a Igreja faz a Deus pelos fiéis falecidos é relevante nesse ponto, pois pode ajudar as pessoas que estão passando pelo fogo purificador.

Terceiro, enfim, há o nível dos que já se afastaram definitivamente de Deus. Estes estão, já após a morte, irrevogavelmente no inferno, que tem diferentes intensidades.

"Juliano contribui para delinear, de modo concreto e acessível, a geografia do mundo que se espera após a morte". ${ }^{54}$ Além de se referir ao alémmorte como passagem "para aquela região [ad illam regionem] à qual nós vamos ao ser o corpo separado da alma", ${ }_{55}$ Juliano menciona por exemplo que, na fase intermediária antes da ressurreição, "as almas ficam contidas em moradas ocultas [abditis receptaculis]", ${ }^{56}$ separadas de acordo com seus níveis de bondade ou maldade. Comenta também que "as almas dos justos que saem dos corpos são introduzidas [...] nas moradas [receptaculis] dos santos". ${ }^{57}$ Em Juliano, "região" e "moradas" não são pensadas analogicamente, mas de modo realmente geográfico ou espacial. São evidências de que "a ideia

\footnotetext{
${ }^{52}$ PFS II, q. 11.

${ }^{53}$ PFS II, q. 36.

${ }^{54}$ GARCÍA, H. G., Notas sobre el papel del Prognosticum futuri saeculi, p. 510.

${ }^{55}$ PFS I, q. 18.

${ }^{56}$ PFS II, q. 9.

${ }^{57}$ PFS I, q. 10.
} 
de uma síntese espacial, de uma localização do céu e do inferno (e também do purgatório) estão já presentes na mente do autor do Prognosticum e, provavelmente, nas de seus leitores" ${ }^{58}$ Uma concepção geográfica corresponde a uma interpretação predominantemente factual dos textos escriturísticos que falam de tempos futuros. Esse mesmo tipo de compreensão factual emerge, por exemplo, quando Juliano considera o problema de onde ficarão os santos no momento da conflagração final do mundo pelo fogo. Ele assinala que "podemos responder que eles ficarão nas partes mais elevadas, onde as chamas não atingirão". ${ }^{59}$ Uma compreensão semelhante transparece ao tocar no tema da localização do derradeiro inferno. Juliano julga inapropriado definir com exatidão em que parte do mundo ele se localizará, mas deixa entendido que se trata de uma questão geográfica, embora não passível de ser definida com precisão. $^{60}$

Não obstante esse tipo de interpretação predominantemente factual, Juliano também incorpora secundariamente elementos simbólicos na interpretação dos textos escriturísticos que falam do futuro escatológico. "O Prognosticum evita o literalismo excessivo". ${ }^{61}$ Juliano emprega interpretações simbólicas, por exemplo, na concepção de que o inferno (antes da ressurreição coletiva final) situa-se embaixo da terra, e no que consiste verdadeiramente $o$ livro da vida que aparece na passagem de Ap 20,12. ${ }^{62}$

No conjunto da reflexão do Prognosticum futuri saeculi, especial relevância tem o conceito de Reino, referido a Deus e Cristo. Na maior parte das vezes ele é referido à realidades do pós-morte. Assinala, outrossim, uma chave de leitura importante que aparece precisamente na última frase da obra, escrita sob forma de pergunta:

O Reino de Deus, amados irmãos, está começando a ficar ao alcance [...] com o passamento deste mundo transitório;

Abracemos o dia que confere a cada um sua morada, e restaura para nós o paraíso e o Reino;

As almas que atingiram algo menos que a santidade perfeita, e partem desta vida nesse estado, podem um dia obter o Reino com os santos. Elas,

\footnotetext{
${ }^{58}$ GARCÍA, H. G., Notas sobre el papel del Prognosticum futuri saeculi, p. 511.

${ }^{59}$ PFS, III, q. 49.

${ }^{60}$ PFS III, q. 43.

${ }^{61}$ POZO, C., La doctrina escatológica del Prognosticon futuri saeculi, p. 195.

${ }^{62}$ PFS II, q. 7, e III, 36.
} 
porém, não são postas imediatamente no Reino celestial logo após deixar o corpo;

Somos conduzidos para o Reino imediatamente após deixar o corpo.

E a frase com a qual Juliano encerra toda a obra é esta:

“de fato, que outro é o nosso fim, senão chegar ao Reino que não tem fim?”. ${ }^{63}$

Algumas poucas vezes, o Reino é identificado também - ao que parece de modo secundário - com a Igreja Católica:

"a Igreja, que já agora é o Reino de Cristo";

"compreendemos que todos os demais falecidos também pertencem à Igreja, que é o Reino de Cristo". ${ }^{64}$

Na síntese do Prognosticum futuri saeculi, o grande evento da Escatologia futura será a vinda de Cristo, quando acontecerão a ressurreição dos mortos e o julgamento de todos. Nessa altura, a obra de Juliano se prolonga numa série de minúcias a respeito das características dos corpos ressuscitados, como por exemplo: a idade, a estatura e o sexo com que a pessoa ressuscitará, se o corpo ressuscitado terá as eventuais deformações de antes da morte ou não, a necessidade ou não de roupas, a ressurreição das partes dos corpos que haviam sido eventualmente devoradas por feras, e até mesmo a questão das unhas e dos cabelos que foram cortados antes da morte. Trata-se, de fato, de "uma problemática algo ociosa, uma excessiva lista de questões em torno do corpo ressuscitado, [quando] talvez uma maior sobriedade teria sido teologicamente preferível". ${ }^{5}$ São reflexões que vão muito além dos dados oferecidos pela revelação divina, que em última instância compõe a única fonte para a fé cristã saber qualquer coisa a respeito das realidades do pós-morte. A categoria dessas reflexões que extrapolam em muito o dado revelado é, a rigor, apenas a de palpite ou opinião teológica.

Contudo, no grande evento da Escatologia futura, para Juliano o mais relevante é que, como a alma "está agora reunida ao corpo", ${ }^{66}$ para os santos a

\footnotetext{
${ }^{63}$ PFS, respectivamente: I, 15; I, 15; II, 10; II, 12; III, 62.

${ }^{64} \mathrm{PFS}$, respectivamente: II, 37; II, 37.

${ }^{65}$ POZO, C., La doctrina escatológica del Prognosticon futuri saeculi, p. 193.

${ }^{66}$ PFS II, q. 11.
} 
ressurreição da carne significará que a visão de Deus será completa e não terá fim. Juliano sublinha que "antes da ressurreição dos corpos, os espíritos dos santos falecidos não veem a Deus da mesma forma que após a ressurreição" ${ }^{67}$ Para Juliano a ressurreição da carne traz claramente algo a mais na visão de Deus. Após a ressurreição da carne, ele assinala que "observaremos, também através do corpo, a Deus incorpóreo que sustenta todas as coisas" ${ }^{68}$ Enfim, após ter completado o julgamento final, Cristo mostrará sua divindade e entregará finalmente a Deus-Pai todo o seu Reino. Juliano acrescenta que "acontecerá então verdadeiramente a plena alegria, quando não estiver faltando mais nenhum dos membros do corpo". ${ }^{69}$ A qualidade da proximidade com Deus após a ressurreição será de tal monta que "Ele, que nos criou, dará Si próprio a nós [Seipsum nobis daturum] como recompensa, como havia prometido, e nada é melhor do que isso". ${ }^{70}$

\section{Sinopse do título e subtítulos da obra}

Por fim, nesta apresentação da obra de Juliano de Toledo, serve de auxílio uma visão completa de todos os subtítulos do Prognosticum futuri saeculi. Mesmo no contexto de um reduzido artigo, isso propiciará uma consideração mais abrangente do conteúdo da obra. É a primeira vez que este conjunto de título e subtítulos é apresentado em português:

Título: Antevisão do mundo que há de vir.

Carta de Juliano a Idálio de Barcelona

A oração que Juliano dirige a Deus

Primeiro livro: Sobre a origem da morte humana.

1. Como a morte entrou no mundo.

2. Deus criou os anjos como imortais, e ameaça com a morte os homens, pecadores.

3. A condição do homem criado, ou a pena de morte que justamente o puniu após o pecado.

\footnotetext{
${ }^{67}$ PFS II, q. 11.

${ }^{68}$ PFS III, q. 54.

${ }^{69}$ PFS II, q. 28.

${ }^{70}$ PFS III, q. 61.
} 
4. Por que se chama morte.

5. Os três tipos de morte corporal.

6. A morte da carne é penosa, mas a maioria das pessoas não experimenta desconforto com ela.

7. Em geral uma morte penosa liberta a alma dos pecados.

8. A morte, que não é um bem, pode ser boa para os bons.

9. Contra aqueles que dizem que, se no batismo o pecado do primeiro homem é absolvido, por que então as pessoas batizadas morrem?

10. Os anjos preparados para receber as almas dos fiéis que morrem e conduzi-las a Deus.

11. Sobre o medo da morte corporal.

12. Sobre o medo que todos experimentam ao querer saber se é preferível temer em vida os diversos tipos da morte, ou suportar um só deles, aquele que lhe cabe.

13. Como consolar aqueles que temem a morte corporal.

14. O cristão não deve temer a morte corporal, porque o justo vive pela fé.

15. Pode-se moderar o medo da morte para que, no dia dela, a abracemos ao invés de temê-la, e o grande número de nossos entes queridos que então nos aguardam.

16. Nossa vontade contrária ao Pai-nosso, no qual oramos para que seja feita a vontade de Deus, mas não querendo ir ao Seu encontro por medo da morte, e o exemplo do frade a quem o Senhor apareceu repreendendo porque tinha medo de deixar o mundo.

17. Para que não nos desesperemos quando estivermos ameaçados de morte iminente.

18. É necessário que cada um, no momento de sua chamada a Deus, intensifique sua oração e seja auxiliado pelas orações dos irmãos.

19. Os fiéis devem cuidar das sepulturas e dos funerais.

20. Para os falecidos é importante que seus corpos sejam enterrados nas igrejas.

21. Para o falecido que é enterrado numa igreja, ajuda muito a fé no auxílio do mártir enterrado ao lado.

22. Os sacrifícios oferecidos pelos fiéis falecidos. 
Segundo livro: Sobre as almas dos falecidos antes da ressurreição final dos corpos.

1. Sobre a diferença entre os paraísos.

2. O lugar do paraíso em que descansam as almas dos santos que deixaram seus corpos.

3. O que significa o "seio de Abraão" no qual são recebidas as almas dos justos.

4. A diferença entre os infernos.

5. Por que se chama inferno.

6. Como é o inferno, ou se eles são materiais.

7. Por que se pensa que o inferno está no subsolo.

8. As almas dos santos vão a Cristo no céu imediatamente após a saída de seus corpos.

9. As almas dos mortos ficam em determinadas moradas.

10. As almas que partem deste mundo sem atingir a santidade perfeita, embora possam obter o Reino junto com os santos, não são colocadas imediatamente no reino celeste.

11. Antes da ressurreição dos corpos, os espíritos dos santos falecidos não verão a Deus da mesma forma que após a ressurreição. Como as almas dos falecidos esperam receber seus corpos.

12. Após a descida de Cristo ao inferno, as almas dos eleitos não estão mais nos lugares onde antes estavam as almas dos Patriarcas, mas sim vão imediatamente para o céu.

13. Assim como as almas dos santos que, após a passagem do corpo, vão para o céu, as dos pecadores vão para o inferno.

14. Aqueles que foram lançados no inferno permanecerão nele perpetuamente.

15. Após a separação do corpo, a alma não fica privada de seus sentidos.

16. A alma se assemelha ao corpo. Devido a essa semelhança, pode experimentar paz e sofrer tormentos.

17. Se a alma, ainda que incorpórea, é atormentada por um fogo corpóreo.

18. O fogo da geena é um só, mas não queima os pecadores do mesmo modo.

19. Depois da morte existe um fogo purificador.

20. Uma coisa é o fogo purificador, segundo a qual se acredita que muitos 
serão salvos, outra coisa é o fogo no qual os ímpios são lançados pelo Cristo juiz.

21. As almas dos mortos são conduzidas para o fogo purificador antes, e não depois, do julgamento final.

22. Se aqueles que serão salvos através do fogo purificador são atormentados até o tempo da ressurreição.

23. A morte da carne corresponde à tribulação do fogo purificador.

24. Se as almas dos mortos podem se reconhecer umas as outras depois da morte da carne. Se aqueles que não se conheceram nesta vida poderão então se conhecer.

25. Se as almas dos bem-aventurados ousam rezar por aqueles que consideram destinados ao inferno.

26. Se as almas dos mortos rezam pela salvação de seus entes queridos que ainda vivem.

27. Se as almas dos falecidos podem se entristecer ou alegrar por causa da salvação de seus entes queridos que ainda vivem, ou se são perturbadas por qualquer tristeza ou preocupação dos que ainda vivem.

28. Os patriarcas, os profetas e os apóstolos e todas as almas dos falecidos que já passaram para a vida de bem-aventurança nos esperam ardentemente para nos alegrarmos com eles, pois não terão alegria completa enquanto se preocuparem com nossos erros.

29. Se os mortos podem saber o que os vivos fazem.

30. Se os mortos podem aparecer visivelmente aos olhos dos vivos.

31. Só as almas dos santos, e não as dos ímpios, sabem o que os vivos fazem.

32. Se após a descida de Cristo ao inferno, a partir da qual o caminho para o céu ficou aberto para os santos, os bons podem ver os maus e suas dores, e os maus podem ver a bem-aventurança dos bons.

33. Contra aqueles que dizem que a alma não vive após a morte.

34. Contra aqueles a quem parece pouco que a alma, após a morte da carne, se sinta alegre ou triste com as coisas que vê, com certa semelhança à realidade do corpo. Ali, as coisas que se veem como alegres ou tristes serão mais intensas do que, aqui, podem ser vistas pela alma durante o sonho. 
35. Que tipo de recompensa as almas dos mortos terão antes da ressurreição no tempo final.

36. Após serem despojadas do corpo, as almas santas veem imediatamente a Deus.

37. As almas dos santos já reinam com Cristo no céu.

Terceiro livro: Sobre a última ressurreição dos corpos.

1. Nenhuma pessoa saberá a hora e o dia do julgamento final.

2. Se o Senhor realizará o julgamento estando em algum lugar especial.

3. Nenhuma pessoa sabe quantos dias o julgamento vai durar.

4. Sobre o terror que será provocado pela vinda de Cristo, que virá para julgar da mesma forma com que foi julgado.

5. Cristo virá para o julgamento precedido por sua cruz, levada nos ombros por seus anjos enquanto Ele desce do céu.

6. A visão do diabo, quando ele for levado para o julgamento, produzirá terror e espanto.

7. Quando Cristo vier para julgar, aparecerá manso para os justos e terrível para os injustos.

8. Justos e injustos verão, com os olhos da carne, a Cristo quando Ele vier para julgar com seu corpo.

9. Como deve ser entendido que somente o Filho, e não o Pai, virá fazer o julgamento.

10. A descida de Cristo do céu para julgar vivos e mortos não é algo que pertence à vida presente.

11. Sobre os tribunais dos juízes.

12. Quem vai sentar com o Senhor para julgar.

13. Deve-se crer que, nos doze tronos indicado por Cristo, não se sentarão apenas doze apóstolos, mas o número completo dos perfeitos, que está implícito no número doze.

14. Sobre a definitiva ressurreição do corpo humano.

15. Quando o sétimo anjo tocar a trombeta, a ressurreição dos mortos acontecerá num piscar de olhos.

16. Todas as pessoas serão ressuscitadas, mas somente os santos serão transformados. 
17. O que ressuscitará sem corrupção não será um corpo vaporoso, mas a carne que agora temos.

18. Como acreditar que os corpos serão espirituais, já que não serão espíritos, mas sim verdadeiramente corpos.

19. Sobre a condição dos corpos na ressurreição futura.

20. Com que idade ou estatura ressuscitarão: velhos, jovens ou crianças.

21. Se as estaturas e as formas dos corpos daqueles que ressuscitam serão iguais ou diferentes, e se os magros vão ressuscitar com a mesma magreza e os gordos com a mesma gordura.

22. Os corpos dos santos serão ressuscitados sem nenhuma deformidade.

23. Não tem sentido perguntar sobre as medidas e a idade do corpo com que os malvados ressuscitarão.

24. Se os homens e as mulheres ressuscitarão nesse mesmo sexo.

25. Os que ressuscitam não terão nenhuma inquietação com comida ou bebida.

26. Nossa natureza não precisará de roupas para o corpo.

27. Os fetos abortados ressuscitarão, porque são seres humanos desde que vivem no seio materno.

28. Como se crê que ressuscitarão aqueles que nascem com um número maior ou menor de membros: com duas cabeças e um corpo, ou dois corpos e uma cabeça, ou outro tipo de alterações dessas.

29. As pessoas que aqui são devoradas pelas feras, ou que são mutiladas por outros tipos de laceração, ao ressuscitar terão seus corpos integrais.

30. Aqueles que saíram doentes desta vida, na ressurreição estarão saudáveis.

31. Se na ressurreição serão retomadas as unhas ou o cabelo que foram removidos na tonsura ou por corte.

32. Como ressuscitarão os que não foram separados da massa da perdição.

33. Sobre o que se seguirá ao julgamento final.

34. A separação dos bons e dos maus.

35. Os anjos separarão os bons dos maus.

36. Separados à direita os bons e à esquerda os malvados, serão abertos os livros, isto é, a consciência de cada um. 
37. Os justos não temerão o mal que ouvirão.

38. Sobre a queda do diabo e a perdição dos ímpios.

39. Qual é o livro a que se referia o apóstolo João ao afirmar que todos aqueles que não estavam escritos no livro da vida seriam enviado para o lago de fogo.

40. Os corpos dos ímpios se conservarão no fogo sem serem consumidos.

41. De que modo aquele futuro fogo queimará os demônios.

42. Sobre a diversidade das penas devido à diversidade dos merecimentos.

43. Contra aqueles que perguntam como será o fogo futuro, ou em que parte do mundo ele se localizará.

44. Após a condenação dos maus se segue a recompensa dos eleitos.

45. Uma vez terminado o julgamento, passará a forma de servo com que Cristo terá realizado o julgamento e Ele entregará o Reino a Deus Pai.

46. O incêndio com que este mundo será consumido.

47. Uma vez concluído o julgamento, começará a existir o novo céu e a nova terra.

48. No novo céu e na nova terra não estarão todos os que ressuscitam, mas só os santos.

49. Contra aqueles que argumentam que, se após o julgamento virá o incêndio do mundo, onde então ficariam os santos para que não serem atingidos pelas chamas.

50. A recompensa dos santos, e como Cristo passará a servir os seus.

51. Os maus desconhecerão o que se fazem os bem-aventurados em sua alegria, mas os bem-aventurados saberão o que acontece no suplício dos condenados.

52. Então poderemos ser levados para o céu e habitar ali com esse corpo que agora temos.

53. Se os movimentos do corpo serão como agora, ou mais sutis.

54. Se veremos a Deus com os olhos corporais com que agora vemos o Sol e a Lua.

55. Veremos a Deus como agora os anjos o veem.

56. Todos os santos terão liberdade mais firme do que nesta vida, mas não pecarão.

57. Ali teremos tanto esquecimento, como memória. 
58. Sobre a diversidade dos merecimentos e dos prêmios. Contudo, ninguém invejará a ninguém.

59. Os santos louvarão a Deus sem cessar.

60. Veremos a Deus ininterruptamente, e Ele mesmo será o fim dos nossos desejos.

61. Deus será nosso prêmio, e todos nossos desejos honestos serão preenchidos de um modo extraordinário.

62. O final sem fim em que agradeceremos infinitamente a Deus.

\section{Conclusão}

A influência da Escatologia do Prognosticum futuri saeculi de Juliano de Toledo se estendeu de modo notável por mais de doze séculos. Um típico tratado De Novissimis do início do século XX mantinha ainda uma estrutura muito semelhante àquela da obra de Juliano, como se vê no esquema a seguir:

\begin{tabular}{l|l|l}
\hline \multicolumn{1}{c|}{$\begin{array}{c}\text { Prognosticum futuri saeculi, } \\
\text { ano } 688\end{array}$} & \multicolumn{2}{c}{ De Novissimis de Louis Billot, ano 1908 } \\
\hline $\begin{array}{l}\text { Livro 1: Sobre a origem da } \\
\text { morte humana. }\end{array}$ & corresponde a & $\begin{array}{l}\text { Capítulo 1: A morte como } \\
\text { término da vida. }\end{array}$ \\
\hline $\begin{array}{l}\text { Livro 2: Sobre as almas dos } \\
\text { mortos e como elas estão antes } \\
\text { da ressurreição final dos corpos. }\end{array}$ & corresponde a & $\begin{array}{l}\text { Capítulo 2: O estado das } \\
\text { almas após a morte, no } \\
\text { inferno, purgatório e céu. }\end{array}$ \\
\hline $\begin{array}{l}\text { Livro 3: Sobre a ressurreição } \\
\text { final e o julgamento. }\end{array}$ & corresponde a & $\begin{array}{l}\text { Capítulo 3: A ressurreição } \\
\text { universal. }\end{array}$ \\
\cline { 3 - 3 } & $\begin{array}{l}\text { Capítulo 4: O juízo final e a } \\
\text { definitiva ordem geral. }\end{array}$ \\
\hline
\end{tabular}

A influência da Escatologia do Prognosticum futuri saeculi foi bem além de condicionar a estrutura dos capítulos das apresentações nesse campo até o século XX. Ela marcou também as ênfases e as lacunas dessas apresentações, e a hermenêutica empregada acerca dos textos da Sagrada Escritura que falam da Escatologia futura.

No campo do que hoje se chama Escatologia, o interesse básico que assinalou Juliano de Toledo assinalou também as apresentações nos 1.200 anos seguintes. O foco da atenção de Juliano consistiu naquele arco significativo que começa com a morte e se estende até o final dos tempos: o chamamos de 
Escatologia futura. Do mesmo modo, até o século XX também o foco dos tratados De Novissimis permaneceu o mesmo daquele do bispo de Toledo.

No Prognosticum é mínimo o exame do que hoje chamamos de Escatologia realizada (o evento Cristo) e Escatologia presente (antes da morte do fiel). Não, evidentemente, que Juliano negasse essas coisas. Muito pelo contrário. $\mathrm{Na}$ introdução de sua obra, especialmente na magnífica oração inicial, aparece de modo evidente a importância vital que o evento Cristo tinha para a vida do bispo Juliano antes de sua morte. A sua reflexão teológica ao longo da obra, contudo, assinala-se por não considerar o que hoje designamos de Escatologia realizada e Escatologia presente. A mesma lacuna vai assinalar os tratados no campo da Escatologia até o século XX.

No Prognosticum aparece também muitas vezes manifestada uma hermenêutica não simbólica daquelas passagens da Sagrada Escritura que falam da Escatologia futura. A verdade transmitida por tais passagens é interpretada a partir de uma chave quase sempre literalista, como se fossem textos que contivessem narrativas factuais a respeito de acontecimentos futuros. A mesma hermenêutica não simbólica dessas passagens (que falam da Escatologia futura) vigorará nos tratados no campo da Escatologia até o século XX, que os interpretarão também como se fossem basicamente textos descritivos a respeito de eventos cronologicamente à frente de nosso tempo. Tal hermenêutica não simbólica não se dá conta que a verdade ensinada por aquelas passagens (sobre a Escatologia futura) não compõe descrições factuais do mundo que há de vir, nem dos últimos acontecimentos da história humana. Compõe, isto sim, grande verdade expressa de modo simbólico. Com isso "pretendemos apenas evidenciar sua condição de imagens e, portanto, a necessidade de evitar a confusão com a própria realidade que com elas se deseja indicar". ${ }^{71}$

A síntese do Prognosticum futuri saeculi se caracterizou também pelo acento posto nos detalhes do corpo ressuscitado, ao invés de se deixar permear pela sobriedade daquilo que é oferecido pela revelação fundamental que, aliás, é a única instância que oferece à Escatologia informações seguras a respeito. Na obra de Juliano, tal ênfase ofusca os elementos da Escatologia coletiva. Isso também teria consequência significativa sobre as apresentações de Escatologia até o século XX. Essas, não raro, se estenderão na descrição das minúcias do indivíduo ressuscitado (indo muito além dos dados oferecidos pela revelação divina, a qual em última instância compõe a única fonte para a

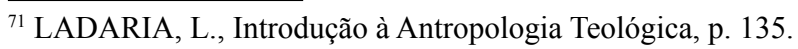


fé cristã conhecer algo acerca do pós-morte), e serão lacunosas na dimensão coletiva e eclesial da ressurreição.

No Prognosticum, Cristo ressuscitado desempenha um papel importante, mas não na visão da substância de Deus que, manifestando-se aos santos parcialmente já logo depois da morte, atingirá seu ápice após a ressurreição da carne no final dos tempos. De fato, Juliano indica que, após a ressurreição coletiva final, a qualidade da proximidade dos santos com Deus será de tal monta que "Ele, que nos criou, dará Si próprio a nós [Seipsum nobis daturum] como recompensa, como havia prometido, e nada é melhor do que isso". ${ }^{72}$ No Prognosticum, tal futuro e definitivo "dar Si próprio a nós", feito por Deus, parece se verificar sem que a humanidade de Cristo ressuscitado exerça qualquer função. "Não há dúvida de que, [em geral] nos tempos subsequentes essa dimensão cristológica da vida eterna tenha sido esquecida, para dar lugar à ênfase da visão da essência divina, em que não é reconhecida nenhuma função à humanidade de Jesus". ${ }^{73}$

No Prognosticum manifesta-se também uma compreensão de Reino (referido a Deus e Cristo) quase sempre como uma realidade que se vive após a morte da pessoa. Apenas duas vezes o Reino - referido a Cristo - é explicitado no Prognosticum indicando realidade antes da morte, e essa realidade aparece ali como a Igreja Católica. Ao longo da reflexão da obra, há uma notável lacuna na identificação do Reino de Deus com a pessoa de Jesus Cristo, em seus gestos, obras e palavras. O Reino de Deus, que no Novo Testamento aparece como categoria central da vida e da pregação de Cristo, e referido à sua pessoa e obra, não vem assim tematizado na obra de Juliano de Toledo. Tal lacuna irá também assinalar os tratados no campo da Escatologia até o século XX.

Nota-se que em sua síntese de Escatologia o bispo Juliano de Toledo teve grande esmero em reunir o testemunho essencial da Sagrada Escritura, junto com os comentários dos autores da Época Patrística. Do ponto de vista metodológico, entretanto, sua obra é assinalada pela ausência total de textos do Magistério.

Do estudo do Prognosticum evidenciamos que, hoje em dia, de fato a Escatologia cristã necessita estabelecer vínculos mais estreitos com os outros tratados sistemáticos, como por exemplo a Antropologia Teológica e Cristologia. Um estudo atual sobre a Escatologia cristã deve estar mais próximo da complexa visão de ser humano que transparece na Sagrada Escritura. Deve igualmente

\footnotetext{
${ }^{72}$ PFS III, q. 61.

${ }^{73}$ LADARIA, L., Introdução à Antropologia Teológica, p. 144.
} 
aproximar Escatologia e Protologia, a reflexão sobre as origens, à luz do que o Magistério e a Teologia aprofundaram consideravelmente a respeito. Esse vínculo mais estreito com os demais tratados da Teologia Sistemática precisa ser levado adiante especialmente tendo por base o conjunto das reflexões no campo da Escatologia cristã trazidas pelo conjunto de três constituições do Concílio Vaticano II: Lumen Gentium, Gaudium et Spes e Dei Verbum.

Enfim, há a questão surgida no século XX queé ainda debatida: "ressurreição na morte + vida eterna fora do tempo" (Escatologia de fase única), ou "ressurreição da carne no final dos tempos" (Escatologia de fase dupla). O que a obra de Juliano de Toledo pode nos trazer sobre isso? Evidentemente não se pode fazer Juliano falar o que ele não falou, e certamente aquela questão não aparece em sua obra. Contudo, alguns elementos metodológicos de sua obra podem lançar luz para ambos os lados desse debate atual. Primeiro, sobre a canonicidade do Antigo Testamento. A obra de Juliano foi escrita mais de 800 anos antes que a Reforma passasse a utilizar a versão encurtada do Antigo Testamento, sem os livros deuterocanônicos. Juliano conhecia e utilizava o Antigo Testamento com tais livros. O juízo que hoje se fará sobre a Escatologia do Antigo Testamento (um elemento importante e inerente àquele debate atual) estará na dependência de qual versão se utiliza. Segundo, que metodologicamente as conclusões da obra de Juliano iam muito além do dado revelado, e esmiuçavam em detalhes as realidades do pós-morte e da vida eterna. Isso nos alerta hoje, naquele debate, a também não incorrermos numa atitude metodológica análoga, e a não nos aferrarmos a teses que extrapolem aquilo que a revelação divina diz de fato a respeito. Nesse sentido, o seguinte princípio mencionado por Karl Rahner na sua obra clássica de 1960 mantém toda a atualidade. ${ }^{74}$ Mesmo dispondo do dado revelado, a plenitude escatológica tem um essencial caráter de ocultação para nós no tempo atual, ou seja, dela temos considerável ignorância e, por isso, vivemos em fé e esperança. Nossa considerável ignorância a respeito da Escatologia futura, mesmo dispondo de elementos divinamente revelados, é um princípio metodológico que necessita sempre ser relembrado.

Em Escatologia, o conhecimento de tão influente obra da história da Teologia revela-se, portanto, útil para nos enriquecer com seus valores, acima resumidos. É também relevante para que, hoje, não repitamos por mimetismo suas lacunas. Se tais lacunas são desculpáveis em Juliano, devido aos limites de acesso à informação inerentes ao seu tempo, não são contudo desculpáveis

${ }^{74}$ RAHNER, K., Theologische Prinzipien der Hermeneutik eschatologischer Aussagen, p. 408-409. 
hoje em dia, a não ser por falta de conhecimento. O conhecimento dos valores e lacunas do Prognosticum futuri saeculi ajudará a apresentar, no modo requerido pelo nosso tempo, o definitivo de Deus que já se manifestou - como Escatologia antecipada e realizada - no evento Jesus Cristo, e que pode se manifestar - como Escatologia presente - na vida dos fiéis antes de sua morte. Tudo isso tendo em conta que, nesta realidade provisória, o definitivo de Deus sempre se manifestará como grão de mostarda, até que chegue a realidade escatológica final, a Escatologia futura.

\section{Referências bibliográficas}

ANCONA, G. Escatologia cristã. São Paulo: Loyola, 2013.

ANCONA, G. Prognosticon futuri saeculi (Juliano de Toledo). In: ANCONA, G. Escatologia cristã. São Paulo: Loyola, 2013. p. 162-164.

BARTH, K. Der Römerbrief. Kaiser: München, 1922. Aufl. 2.

BARTH, K. Die Auferstehung der Toten. Kaiser: München, 1924.

BILLOT, L. De Novissimis. 3 ed. Roma: Officina Polygraphica, 1908. COMISSÃO TEOLÓGICA INTERNACIONAL. Algunas cuestiones actuales de Escatología. Roma, 1990. Disponível em: <www.vatican.va/ roman_curia/congregations/cfaith/cti_documents/rc_cti_1990_problemiattuali-escatologia_sp.html>. Acesso em: 30. Nov. 2017.

CONGAR, Y. Le purgatoire. In: AUZELLE, R. (Org.). Le mystère de la mort et sa célébration. Vanves, 27-29 avril 1949. Paris: Cerf, 1956. p. 279-336.

CULLMANN, O. Christus und die Zeit. Zürich: Evangelischer, 1946.

DANIÉLOU, J. Christologie et eschatologie. In: GRILLMEIER, A.; BACHT, H. (Org.). Das Konzil von Chalkedon. Chalkedon heute. Würzburg: Echter, 1954. p. 269-286. Band. 3.

DODD, C. H. The Parables of the Kingdom. London: Nisbet, 1935.

GARCÍA HERRERO, G. Notas sobre el papel del Prognosticum futuri saeculi de Julián de Toledo en la evolución de la idea medieval del purgatorio. Antigüedad y Cristianismo, n.23, p. 503-513, jan./ dez. 2006.

GONZÁLEZ RUIZ, R. San Julián de Toledo en el contexto de su tiempo. Anales Toledanos, n.32, p. 7-21, jan./ jun.1996. 
HILlgARTH, J. N. El Prognosticon futuri saeculi de San Julián de Toledo. Analecta Sacra Tarraconensia, v.30, n.1, p. 5-61, jan./jun. 1957.

JEREMIAS, J. Die Gleichnisse Jesu. Zürich: Zwingli, 1947.

JULIANO DE TOLEDO. Pronóstico del mundo futuro. Madrid: Ciudad Nueva, 2013. (Biblioteca de Patrística, 94).

JULIANO DE TOLEDO. Prognosticum futuri saeculi. Foreknowledge of the world to come. New York: Newman, 2010. (Ancient Christian Writers, 63).

JULIANO DE TOLEDO. Prognosticon futuri saeculi libri tres. Paris: 1862. col. 453-524. (Migne Patrologiae Cursus Completus Series Latina Prior, 96).

JULIANO DE TOLEDO. Prognosticum futuri saeculi libri tres. Turnholt: Brepols, 1976. p. 3-126. (Corpus Christianorum Series Latina, 115).

LADARIA, L. De Agostinho a Juliano de Toledo. O primeiro tratado de Escatologia. In: SESBOÜÉ, B. (Org.). História dos dogmas. O homem e sua salvação. São Paulo: Loyola, 2003. p. 369-371. t.2.

LADARIA, L. Introdução à Antropologia Teológica. São Paulo: Loyola, 2011.

LIBANIO, J. B.; BINGEMER, M. C. Escatologia cristã. O novo céu e a nova terra. Petrópolis: Vozes, 1985.

MOLTMANN, J. Theologie der Hoffnung. München: Kaiser, 1964.

MURAD, A. et al. Da terra ao céu. Escatologia cristã em perspectiva dialogal. São Paulo: Paulinas, 2016.

NOCKE, F. J. Escatologia. In: SCHNEIDER, T. (Org.). Manual de Dogmática. 5.ed. Petrópolis: Vozes, 2012, p. 339-426. v.2.

PANNENBERG, W. Dogmatische Thesen zur Lehre von der Offenbarung. In: PANNENBERG, W. (Org.). Offenbarung als Geschichte. Göttingen: Vandenhoeck-Ruprecht, 1961. p. 91-114.

PIO XII, PP. Encíclica Divino afflante Spiritu (DAS). Acta Apostolicae Sedis, v.10, n.35, p. 297-325, jan./dez. 1943.

POZO, C. La doctrina escatológica del Prognosticon futuri saeculi de San Julián de Toledo. Estudios Eclesiásticos, v.45, n.173, p. 173-201, abr.jun. 1970.

RAHNER, K. Theologische Prinzipien der Hermeneutik eschatologischer Aussagen. In: RAHNER, K. Schriften zur Theologie. Einsiedeln: Benziger, 1960. p. 401-428. Band IV. 
SCHMAUS, M. A fé da Igreja. Justificação do indivíduo e Escatologia. Petrópolis: Vozes, 1981, p. 150-242. v.6.

SCHWEITZER, A. Von Reimarus zu Wrede. Eine Geschichte der LebenJesu-Forschung. Tübingen: Mohr-Siebeck, 1906.

STANCATI, T. Alle origini dell'Escatologia cristiana sistematica. Il Prognosticon futuri saeculi di san Giuliano di Toledo (sec. VII). Angelicum, v.73, n.3, p. 400-433, jul./set. 1996.

STANCATI, T. Preface and Introduction. In: JULIANO DE TOLEDO. Prognosticum futuri saeculi. Foreknowledge of the world to come. New York: Newman, 2010. p. xi-362.

TEILHARD DE CHARDIN, P. Le Phénomène humain. Paris: Seuil, 1955.

TEILHARD DE CHARDIN, P. L'Avenir de l'homme. Paris: Seuil, 1959.

TROELTSCH, E. Glaubenslehre. Nach Heidelberger Vorlesungen aus den Jahren 1911 und 1912. München-Leipzig, 1925.

VON BALTHASAR, H. U. Geschichte des eschatologischen Problems in der modernen deutschen Literatur. Zürich: Zürich Universität, 1930.

VON BALTHASAR, H. U. Eschatologie. In: FEINER, J. et al. (Org.). Fragen der Theologie heute. Einsiedeln: Benziger, 1957. p. 403-421.

WEISS, J. Die Predigt Jesu vom Reiche Gottes. Göttingen: VandenhoeckRuprecht, 1892.

WICKI, N. Das Prognosticon futuri saeculi Julians von Toledo als Quellenwerk der Sentenzen des Petrus Lombardus. Divus Thomas, Freiburg, v.31, n.1, p. 349-360, jan./dez. 1953.

César Andrade Alves

Doutor em Teologia pela Pontificia Università Gregoriana Docente de Teologia na Faculdade Jesuíta de Filosofia e Teologia Belo Horizonte / MG - Brasil E-mail: cesar.alves@faculdadejesuita.edu.br

Recebido em: 14/11/17 Aprovado em: 26/07/18 